Www.jmscr.igmpublication.org

Impact Factor (SJIF): 6.379

Index Copernicus Value: 79.54

ISSN (e)-2347-176x ISSN (p) 2455-0450

crossrefDOI: https://dx.doi.org/10.18535/jmscr/v6i12.08

Journal Of Medical Science And Clinical Research

IGM Publication

An Official Publication of IGM Publication

\title{
Clinical profile and outcome in elderly patients with epilepsy in a neurology tertiary care centre in eastern India
}

\author{
Authors \\ Dr Meghraj Singh Patel ${ }^{1}$, Dr Ritesh Yadav ${ }^{2}$ \\ ${ }^{1}$ Assistant Professor Chirayu Medical College Bhopal, MP, India \\ ${ }^{2}$ Senior Resident NSCB Medical College Jabalpur, MP, India
}

\begin{abstract}
Background: Epileptic seizures (ESs) are common neurological problem in the elderly. The underlying etiology and treatment of ESs is different in elderly due to underlying comorbidities and physiological changes with aging. Precise data on this topic are not readily available from developing countries.

Aims: To study the clinical presentation, EEG and Neuroimaging correlation and response to drug treatment in elderly with ESs.

Setting and Design: longitudinal descriptive study.

Material and Methods: The patients were selected who had ESs first time after 60 years of age, were interviewed, examined, investigated and follow up for 3 months to see the response of drug treatment. Data were recorded on pre-set proforma.

Statistical analysis: Used simple percentage and proportion to analysed the data.

Results: There were 66 patients (38 male). Mean age was 62.33 year. ESs was partial with or without secondary generalization in $62.12 \%$ of cases. Symptomatic localization related epilepsy (LRE) was most common syndrome (66.67 \%). MRI suggestive of stroke as a most identifying etiology in $43.93 \%$ of patients. Ratio of patients on monotheraphy and polytheraphy was 2.3:1. At the time of last follow up percentage of patients in Engel's score 0-4 category were increased from $4.54 \%$ to $54.54 \%$.

Conclusion: LREs were the most common type of ESs (76\%) with stroke were most common identifying lesions on MRI (43.93\%). Most of the patients were on monotherapy (69.7\%). Significant reduction in ESs frequency was seen at the time of last follow up.

Keywords: Elderly, Epileptic seizures, Engel's score.
\end{abstract}

\section{Introduction}

A seizure is a paroxysmal event due to abnormal, excessive, hypersynchronous discharges from an aggregate of central nervous system neurons ${ }^{1}$. Epilepsy is a condition characterized by recurrent seizures, unprovoked by any immediate identified cause $^{1}$. Epilepsy was considered as a disease of childhood and young adult but now it is known that old age is the most common time in life to develop epilepsy. The differential diagnosis of seizures in the elderly is broad and includes syncope, transient ischemic attack, transient global amnesia, or episodic vertigo. Making a secure diagnosis is difficult in this age group. The clinical manifestations of seizures and the causes of epilepsy can be different in older people than in younger ones. Age related physiological changes can affect the pharmacokinetics and pharmacodynamics of antiepileptic drugs. The prognosis for elderly epilepsy patients treated with 
anti-epileptic is generally good as compared to young. As there is lack of studies on elderly patient with epilepsy in India, particularly in eastern part. That has stimulated my thought to work in this field. This study will provide the information regarding demographic data; clinical presentations of seizures in elderly; types of epilepsy common in this age group, underlying etiology; electroencephalography (EEG) and neuroimaging changes; treatment with antiepilepileptic drugs (AEDs)(class of drug, number of different AEDs required, effective dose, adverse effect, response to treatment). This study will provide better understanding in diagnosis and effective management of epilepsy in elderly patients.

\section{Objectives}

1. To study the presenting semiology of seizures and their syndromic classification in elderly patients.

2. To study different aetiologies of epilepsy in elderly.

3. To study pharmacotherapy and outcome of treatment.

\section{Material and Methods}

This prospective follow-up study includes patients $\geq 60$ year of age, diagnosed as Epilepsy as per International League Against Epilepsy (ILAE) definition $1989^{1}$, for the first time, reported to Department of Neurology, Bangur Institute of Neurosciences Kolkata between Jan 2012 to Oct 2013. Patients were evaluated after taking written informed consent, for age at presentation, gender, seizure semiology, seizure frequency, neurological examination, EEG and Magnetic Resonance Imaging (MRI) features. In addition to this, history of concomitant neurological and systemic illness, exposure with current AEDs and other medicine was recorded. The AEDs taken by patients were recorded. Number of patients on monotheraphy or polytheraphy was noted and were followed up for 3 months to see the response of drug therapy on epilepsy. All evaluated data were recorded in a database (Microsoft Excel software) and then analysed. This study was carried out with permission of hospital ethical committee.

Table No 1 Distribution of patients according to age, seizure type, neurological and systemic illness

\begin{tabular}{|c|c|c|c|}
\hline Serial No & & Number & $\%$ \\
\hline \multicolumn{4}{|c|}{ Distribution of patients according to sex and age group } \\
\hline & Age group & Male & Female \\
\hline 1. & $61-70$ yrs & 39 & 21 \\
\hline 2. & $71-80$ yrs & 4 & 1 \\
\hline \multirow[t]{2}{*}{3.} & $\geq 80$ yrs & 1 & 0 \\
\hline & Total & 44 & 22 \\
\hline \multicolumn{4}{|c|}{ Distribution of patients according to seizure type } \\
\hline \multirow[t]{3}{*}{1.} & Partial Seizures & 48 & 72.72 \\
\hline & Simple Partial & 26 & 39.39 \\
\hline & Complex Partial & 22 & 33.33 \\
\hline 2. & Generalised & 13 & 19.7 \\
\hline 3. & Undetermined & 3 & 4.54 \\
\hline 4. & Status Epilepticus & 2 & 3 \\
\hline \multicolumn{4}{|c|}{ Postictal confusion period } \\
\hline 1. & No post ictal confusion & 13 & 19.66 \\
\hline 2. & $<10$ minute & 24 & 34.36 \\
\hline 3. & $\geq 10$ minute & 29 & 43.94 \\
\hline 4. & $>30$ minute & 11 & 16.67 \\
\hline \multicolumn{4}{|c|}{ Distribution of Infarct and haemorrhage } \\
\hline \multirow[t]{3}{*}{1.} & Infarct & 23 & 34.84 \\
\hline & Cortical plus subcortical & 18 & 27.27 \\
\hline & Subcortical & 5 & 7.57 \\
\hline 2. & Hemorrhage & 6 & 9.09 \\
\hline
\end{tabular}




\begin{tabular}{|c|c|c|c|}
\hline & Lobar hemorrhage & 2 & 3 \\
\hline & Ganglionic region hemorrhage & 4 & 6 \\
\hline & urological illness & & \\
\hline 1. & CVA & 29 & 42.42 \\
\hline 2. & Head injury & 5 & 7.58 \\
\hline 3. & Tumor/metastasis & 4 & 6 \\
\hline 4. & Vascular Dementia & 4 & 6 \\
\hline 5. & Vascular PD & 4 & 6 \\
\hline 6. & Post encephalitis & 3 & 4.54 \\
\hline 7. & Peripheral neuropathy & 3 & 4.54 \\
\hline & temic illnesses & & \\
\hline 1. & Hypertension & 27 & 40.9 \\
\hline 2. & Diabetes & 12 & 18.18 \\
\hline 3. & Cardiovascular disorder & 7 & 5.83 \\
\hline 4. & Respiratory disorder & 2 & 3 \\
\hline 5. & Psychiatric illness & 2 & 3 \\
\hline 6. & Other & 2 & 3 \\
\hline
\end{tabular}

Table 2 Syndromic classification of patients

\begin{tabular}{|c|c|c|c|}
\hline \multirow{2}{*}{\multicolumn{2}{|c|}{ Syndrome }} & \multicolumn{2}{|c|}{ Total } \\
\hline & & No & $\%$ \\
\hline \multirow{3}{*}{$\begin{array}{l}\text { Localization Related Epilepsy(LRE) } \\
(\mathrm{n}=57 ; 86.36 \%)\end{array}$} & Symptomatic & 54 & 81.81 \\
\hline & Cryptogenic & 03 & 4.54 \\
\hline & Idiopathic & 0 & 0 \\
\hline \multirow[t]{3}{*}{ Generalized Epilepsy (GE)(n=6; 9.09\%) } & Symptomatic & 0 & 0 \\
\hline & Cryptogenic & 6 & 9.09 \\
\hline & Idiopathic & 0 & 0 \\
\hline \multicolumn{2}{|l|}{ Undetermined (U) $(\mathrm{n}=3 ; 4.54 \%)$} & 3 & 4.54 \\
\hline \multicolumn{2}{|l|}{ Total } & 66 & 100 \\
\hline
\end{tabular}

Table 3 EEG and neuroimaging findings of patients

\begin{tabular}{|c|c|c|c|c|c|}
\hline & \multicolumn{2}{|c|}{ Normal } & \multicolumn{3}{|c|}{ Abnormal } \\
\hline & No & $\%$ & & No & $\%$ \\
\hline \multirow{10}{*}{$\begin{array}{l}\text { EEG }(\mathrm{n}=66) \\
\begin{array}{l}\text { MRI Brain } \\
(\mathrm{n}=66)\end{array}\end{array}$} & 58 & 87.88 & Epileptiform Discharge & 8 & 12.12 \\
\hline & \multirow[t]{9}{*}{20} & \multirow[t]{9}{*}{30.3} & Infarct & 23 & 34.84 \\
\hline & & & Intracranial haemorrhage & 6 & 9.09 \\
\hline & & & Granuloma & 4 & 6 \\
\hline & & & Diffuse cerebral atrophy & 3 & 4.54 \\
\hline & & & Tumor/metastasis & 4 & 6 \\
\hline & & & Gliosis & 2 & 3 \\
\hline & & & Hemorrhagic contusion & 2 & 3 \\
\hline & & & Cavernoma & 1 & 1.5 \\
\hline & & & ADEM & 1 & 1.5 \\
\hline
\end{tabular}

Table 4 Seizure frequency at the time of registration and last follow up

\begin{tabular}{|l|c|c|}
\hline Seizure Frequency & At the time of registration & Last Follow up \\
\hline Engel's Score 0-4 & 4 & 34 \\
\hline Engel's Score 5-6 & 9 & 14 \\
\hline Engel's Score 7-12 & 53 & 18 \\
\hline
\end{tabular}

Table 5 Pharmacotheraphy

\begin{tabular}{|l|c|c|c|c|}
\hline & At the time of registration & Percentage (\%) & Last follow up & Percentage (\%) \\
\hline Monotherapy & 46 & 69.7 & 52 & 80.3 \\
\hline Polytherapy & 20 & 30.3 & 14 & 21.21 \\
\hline Levetiracetam & 35 & 53 & 40 & 60 \\
\hline Phenytoin & 33 & 50 & 28 & 42.42 \\
\hline Oxcarbazepine & 5 & 7.57 & 4 & 6 \\
\hline Carbamazepine & 2 & 3 & 2 & 3 \\
\hline Valproate & 7 & 10.6 & 7 & 10.6 \\
\hline Clobazam & 5 & 7.57 & 5 & 7.57 \\
\hline
\end{tabular}




\section{Results and Analysis}

This present study includes total 66 patients who were presented with diagnosis of epilepsy in elderly first time at or above 60 years of age.

As showed in table1, among total 66 patients, 44 were males and 22 were females with a male female ratio of $2: 1$. The maximum number of patients were in the 60-70 year age group $(n=60: 90 \%)$. Majority of patients were presented with partial seizure $(\mathrm{n}=48 ; 72.72 \%)$. Patients presented with simple partial seizures (SPS) is relative more $(n=26 ; 39.39 \%)$ compared to complex partial seizures (CPS) $(\mathrm{n}=22 ; 33.33 \%)$. Only $19.7 \%$ patients presented as generalized seizure.

In $43.94 \%$ patients had post ictal confusion period lasted for $\geq 10$ minutes and in $16.67 \%$ the duration of post ictal confusion was $>30$ minutes. The majority of infarct was both cortical plus subcortical $(n=18 ; 27.27 \%)$. Total five patients had only subcortical infarct. Ganglionic region haemorrhage was more common than lobar haemorrhage $(4: 2 ; 6 \%: 3 \%)$.

Associated neurological illnesses were present in $38(57.58 \%)$ patients. The most common associated neurological illness was stroke in 29 $(42.42 \%)$ patient. In systemic illnesses ( $n=$ $32,48.48 \%$ ) hypertension was associated in $40.9 \%$ patients and $24.24 \%$ patients were diabetic.

As showed in table 2, Localization related epilepsy (LRE) was most common syndrome $(\mathrm{n}=57,81.81 \%)$. Among the LRE, symptomatic LRE was most common type $(\mathrm{n}=54 ; 81.81 \%)$. Six (9.09\%) patients were classified as cryptogenic generalized epilepsy. In $3(4.54 \%)$ patients the epilepsy classification could not be possible so they were kept in undetermined group.

As per table3, EEG was performed in all patients but in most of the patients it showed normal result $(\mathrm{n}=58 ; 87.88 \%)$. MRI Brain was performed in all patients. The most common radiological finding was in favour of vascular insult in 29 (43.94\%) patients including Infarct in 23 patients followed by Haemorrhage in 6 patients. Other findings were in favour of diffuse cerebral atrophy, haemorrhagic contusion, tumour/metastasis, focal gliosis, cavernoma and Acute disseminated encephalomyelitis (ADEM).

As per table4, majority of patients $(n=53 ; 80.3 \%)$ were in Engel's score range 7-12 at the time of presentation. At the time of last follow up total 34 $(51.51 \%)$ patients were in Engel's score range of $0-4$.

As showed in table5, At the time of registration $69.7 \%$ of patients were on monotheraphy. Two most common AEDs taken by patients were levetiracetam $(n=35 ; 53 \%)$ and phenytoin $(n=33$; $50 \%$ ). The other AEDs taken by patients were oxcarbazepine, sodium valproate, clobazam, phenobarbitone.At the time of last follow up 80.3 $\%$ on monotheraphy. Patients who were on phenytoin were $28(42.42 \%)$ and on levetiracetam were $40(60 \%)$.

\section{Discussion}

We have analyzed the demographic and clinical characteristics of 66 patients of epilepsy aged 60 years or more attending Bangur Institute of neurosciences, Kolkata.

In our study male patients were $66.67 \%$. The maximum number of patients were in the 61-70 years age group $(n=60 ; 90 \%)$. In a study from south India ${ }^{2}$ total male patients were $68(58.6 \%)$, with age 60 years or more.

In this study majority of patients were presented with partial seizure $(n=48 ; 72.72 \%)$ with or without secondary generalization. Patients presented with SPS were relative more $(n=26$; $39.39 \%$ ) compared to CPS ( $\mathrm{n}=22 ; 33.33 \%)$. Only $19.7 \%$ patients presented as generalized seizure. Previous studies $3,4,5,6,7.8 .9 .10 .11$ reported complex partial seizures are the most common seizure type, accounting for nearly $40 \%$ of all seizures in the elderly population. Both simple and complex seizures may spread and develop into generalized tonic-clonic seizures (GTCS). Many of these were clinically misperceived as generalized (i.e. partial seizure with secondary generalization); a situation where the contribution of brain imaging appeared crucial by identifying a related cerebral lesion 
which suggested their focal nature. In our study 13 patients presented to us as a GTCS but after investigation the focus was found in 7 patients in MRI Brain so they are classified as symptomatic LRE.

The possibility of generalized epilepsy commencing in old age is remote, and given patient aged over 60 who has developed epilepsy we should consider focal epilepsy even when there is no clear focal start to the crises ${ }^{12}$.

Two of the patients in our study were presented with status epilepticus. In one patient the underlying cause was stroke and in other patient no underlying cause was identified. As previously reported the most common underlying cause of status epilepticus in elderly is stroke ${ }^{13}$. In present study the exact semiology was not available because the patient does not remember anything about the event and no eyewitness was available. Patients were found in unconscious state in the morning and regain consciousness later. These patients were classified as seizure of undetermined semiology. It is well known that exact semiology of seizure in elderly is not available as generally these patients live isolated.

In the present study LRE was most common syndrome $(n=57,86.36 \%)$. Among the LRE, symptomatic LRE were most common epilepsy $(\mathrm{n}=54 ; 81.81 \%)$. six $(9.09 \%)$ patients were classified as cryptogenic generalized epilepsy. In $3(4.54 \%)$ patients the epilepsy classification could not be possible so they were kept in undetermined group. According to Hauser W (1992) most seizures in the elderly are caused by a focal area of damage to the brain, the most common seizure types are localization related ${ }^{3}$. Our study reported symptomatic LRE in $81.81 \%$ of patients which was slightly higher than the Japanese study in which $76.3 \%$ patients had symptomatic $\mathrm{LRE}^{12}$. Other study reported two thirds of epilepsies which develop in elderly are symptomatic, and the other third are cryptogenic ${ }^{3}$. In other study from south India there were only $67.62 \%$ with $\mathrm{LRE}^{2}$. The difference may be due to different selection criteria of the patients. In present study we included only those patients who developed epilepsy for first time after 60 years of age and in study from south India all epilepsy patients more than 60 years old were included.

The EEG was normal in most of the patients $(\mathrm{n}=58 ; 87.88 \%)$, similarly study by Hauser Whad also confirmed the low diagnostic contribution of EEG as earlier reported ${ }^{3}$.

The most common etiology in present study was vascular insult ( $\mathrm{n}=29 ; 43.94 \%)$ including Infarct in 23 patients followed by Hemorrhage in 6 patients. Other etiologies were hemorrhagic contusion, tumour/metastasis, focal gliosis, cavernoma and ADEM. Stroke was also the leading cause among epilepsy in elderly. These results are consistent with previous literature ${ }^{3,11}$.

The majority of infarct was both cortical and subcortical $(n=18 ; 27.27 \%)$. Total five patients had only subcortical infarct. Ganglionic region hemorrhage was more common than lobar hemorrhage ( $4: 2 ; 6 \%: 3 \%)$. In the study by Bladin $\mathrm{C}$ et alshowed cortical involvement is among the most reliable risk factor for post stroke epilepsy ${ }^{15}$. Any stroke including that only subcortical involvement may occasionally be associated with seizure. One reason could be in earlier studies using less sensitive neuroimaging technique, may not have detected concomitant small cortical lesion that could cause ictal activity. The mechanism by which deep hemispheric subcortical lesions causes seizure is not clearly under stood. In a series of 123 patients, seizure incidence was highest with bleeding in to lobar cortical structure (54\%), low with basal ganglionic hemorrhage (19\%), and absent with thalamic hemorrhage ${ }^{15}$. Caudal involvement of basal ganglia and temporal or parietal involvement within the cortex predict seizure ${ }^{16}$. A study done by Guye et al., 2006, shows that the medial pulvinar nucleus harbor ictal activity in patients with temporal lobe epilepsy and diffusionweighted imaging (DWI) hyperintensities in patients with complex partial status epilepticus. Ipsilateral thalamic hyperintense DWI lesions may be observed after prolonged partial SE in a study 
done by Katramados et $\mathrm{al}^{17}$., 2009. Patients with ring chromosome 20 , a syndrome characterized by frequent episodes of drug-resistant complex partial status of presumed frontal or frontotemporal origin, exhibit decreased [18F] fluoro- L-Dopa uptake in the caudate and putamen nuclei during ictal discharges observed by Biraben et al., $2004^{18}$. This finding led to the hypothesis that striatal dopaminergic activity deficit, and the consequent impaired capacity of the basal ganglia to interrupt seizures, might play a key role in the genesis of prolonged seizures in these patients.

The most common associated neurological illness was stroke in 29 (43.94\%) patients. Other were $\mathrm{h} / \mathrm{o}$ head injury (7.58\%), Vascular dementia (6\%), vascular Parkinsonism (6\%), tumour/ metastasis (6\%), peripheral neuropathy $(4.54 \%)$, post encephalitis $(4.54 \%)$.

Total $48 \%$ of patient had associated systemic illness. Hypertension was associated in $40.9 \%$ patients and $24.24 \%$ patients were diabetic. In a large cohort from USA, $64 \%$ of patients presented clinically with hypertension, less than one third of patients were diabetic ${ }^{2}$. The possibility of developing seizure increases fivefold in hypertensive patients ${ }^{2}$.

At the time of registration $69.7 \%$ of patients were on monotheraphy. In previous study polytheraphy were employed in $80 \%$ and rest were on monotheraphy ${ }^{2}$. In our study we took newly diagnosed patients, it may the reason of more patients on monotheraphy.

Two most common AEDs taken by patients in present study were levetiracetam $(\mathrm{n}=35 ; 53 \%)$ and phenytoin $(n=33 ; 50 \%)$. The other AEDs taken by patients were oxcarbazepine, sodium valproate, clobazam, phenobarbitone.

Levetiracetam was used by 35 patients at the time of registration and by 40 patients at the time of last followed up either as monotherapthy or in polytheraphy. Availability of intravenous formulation and lack of interactions with concomitant used drug make the levetiracetam as a good choice in elderly patients with epilepsy. Similar study using levetiracetam in epilepsy in patients aged 65 and older shows a better response than the other group as whole ${ }^{19}$. Another study done by Bazil CW et al (2002) found a better response to LEV in late-onset epilepsy ${ }^{20}$.

Phenytoin was taken by $50 \%$ patients at the time of registration and by $28(42.42 \%)$ patients at the time of last follow up. In a previous study done by Garrard J et al. (2000) phenytoin was used by $61.84 \%$ of elderly patients ${ }^{21}$. The proven effectiveness, availability and low cost make phenytoin a favorable drug for initiation in the elderly. However, elderly persons are more prone to the adverse effects of PHT such as cardiac arrhythmia, hypotension, ataxia and peripheral neuropathy and osteoporosis. PHT is approximately $90 \%$ bound to plasma proteins and its free fraction is likely to be higher in the elderly who have reduced serum albumin levels ${ }^{22}$.

At the time of last follows up $80.3 \%$ on monotheraphy. This finding was consistent with previous retrospective study in which seizures in $88 \%$ of the 90 patients could be managed with monotherapy ${ }^{23}$.

\section{Conclusion}

The present study is concerned with the clinical characteristics found in a consecutive series of patients with epilepsy in elderly. It has to be considered that this is one of only a few studies on this entity that have been carried out in a developing country like India and especially in eastern India. Our study also reflects the usefulness of clinical knowledge in identifying seizure in elderly that will help in choosing appropriate investigations. It also helps in further classification of seizure and their management. As the outcome of treatment of epilepsy is very good in elderly we should have a low threshold in starting and AED but at the same time the concurrent illness, drugs and side profile of the AED should we kept in mind.

\section{References}

1. Berg Anne $\mathrm{T}$ et al, Revised terminology and concepts for organization of seizures 
and epilepsies: report of the ILAE Commission on Classification and Terminology, 2005-2009.Epilepsia. 2010 Apr;51(4):676-85.

2. Nisha Jacob, Sanjeev V Thomas, PS Sarma. Anti epileptic drug usage and withdrawal in elderly persons with epilepsy. Annals of Indian academy of Neurology 2007; 10:34-38

3. Hauser W. Seizures disorders: the changes with age. Epilepsia 1992;33(4Suppl.):S614.

4. Jallon P, Goumaz M, Haenggeli C, Morabia A. Incidence of first epileptic seizures in the canton of Geneva, Switzerland. Epilepsia1997;38:547-52.

5. Loiseau J, Loiseau P, Duche B et al.: A survey of epileptic disorders in southwest France: seizures in elderly patients. Ann Neurol 1990;27:232-

6. De Toledo JC. Changing presentation of seizures with aging: clinical and etiological factors. Gerontology 1999;45:329-35.

7. Ettinger AB, Shinnar S. New-onset seizures in an elderly hospitalized population. Neurology 1993;43:489-92.

8. Granger $\mathrm{N}$, Convers $\mathrm{P}$, Beauchet $\mathrm{O}$ et al. First seizure in subjects over 60 years: electroclinical and etiological data. Rev Neurol 2002;158:1088-95.

9. McAreavey MJ, Ballinger BR, Fenton GW. Epileptic seizures in elderly patients with dementia. Epilepsia1992;33:657-60.

10. Paradowski B, Zagrajek M. Epilepsy in middle-aged and elderly people: a three year observation. Epileptic Disord 2005;7:91-5.

11. Tallis R, Boon P, Perucca E, Stephen L. Epilepsy in elderly people: management issues. Epileptic Disord 2002;4(2 Suppl.):S33-9

12. Hiyoshi T, Yagi K. 2000. Epilepsy in the elderly. Epilepsia, 41(Suppl 9):31-5
13. Waterhouse EJ, Delorenzo RJ, Status epilepticus in older patients: epidemiology and treatment options. Drug Aging 2001;18(2):133-42.

14. Drury I, Beydoun A. Interictal epileptiform activity in elderly patients with epilepsy. Electroencephalogr Clin Neurophysiol1998;106:369-73.

15. Bladin C, Alexandroy A, Bellavance A, et al. seizure after stroke: a prospective multicenter study. Arc Neurol. 2000;57:1617-1622

16. Faught E, Peter D, et al. Seizure after primary intracerbral hemorrhage. Neurology 1989;39 1089-1093

17. Katramados $\mathrm{AM}^{1}$, Burdette $\mathrm{D}$ et al Periictal diffusion abnormalities of the thalamus in partial status epilepticus. Epilepsia. 2009 Feb;50(2):265-75.

18. Biraben A, Semah F et al, PET evidence for a role of the basal ganglia in patients with ring chromosome 20 epilepsy. Neurology 2004 63:73-77.

19. Ferrendelli JA, French J, Leppik I, et al. Use of levetiracetam in a population of patients aged 65 years and older: a subset analysis of the KEEPER trial. Epilepsy Behav. 2003;4:02-9.

20. Bazil CW, Rose A, Resor S, et al. Levetiracetam may be more effective for late-onset partial epilepsy. Arch Neurol. 2002;59:1905-8.

21. Garrard J, Cloyd JC, Gross C et al. Factors associated with antiepileptic dr ug use among elderly nursing home residents. J GeriontolA Biol Sci Med Sci 2000; 55:38492.

22. Greenblatt DJ . Reduced serum albumin concentration in the elderly: A report from the Boston Collaborative Drug Surveillance Program. J Am Geriatr Soc 1979;27:202.

23. Gupta S Naheedy ME lias DR ubino F Postinfarction seizure: a clinical study. Stroke,1988;19:1477-1481. 